\title{
INVESTIGATION OF FIVE E. COLI SEROGROUPS (APEC) ISOLATED FROM CASES OF ARTHRITIS OF COMMERCIAL MEAT CHICKEN IN MIDDLE AND COASTAL REGIONS OF SYRIA
}

\author{
NAWAL ALKARAWANI and AZZAM KURDI \\ Master Degree of Poultry Diseases, \\ Faculty of Veterinary Medicine, AL Baath University, Syria
}

\section{ABSTRACT}

Received at: 26/5/2013

Accepted: 1/7/2013
A total of 188 joint samples has been collected from commercial meat chicken with lameness from poultry farms in the middle (Hama) and coastal regions (Tartos) of Syria. These joint samples were taken from cases of arthritis and included hip, knee, hock, foot pad .Surfaces of joints were disinfected. Joint samples were cultured on (MacConkey agar - EMB agar) and identified on the basis of biochemical tests, by using HiMotility biochemical kit for E.coli. So, we obtained in total $(72.9 \%)$ isolates from infected joint samples. $(74.1 \%)$ isolates from Hamaand $(70.8 \%)$ isolates from Tartos. The rates of isolation of E. coli were (20.4\%) from knee joints, (14.6\%) from hip joints and (13.9\%) from foot joints, but the higher rate was from hock joints (88.3\%). The motility of all isolates as one of the virulence factors were tested and found that (95.3\%) from Hama and $(95.1$ $\%)$ from Tartos isolates were motile. The hemolysis, as another virulence factor, was tested in all isolates and we found that (95.7 \%) of Hama and (94.6\%) of Tartos isolates were hemolytic. Isolates were serotyped by agglutination test with specific antisera of somatic antigen to five serogroups $\mathrm{O} 1, \mathrm{O} 6, \mathrm{O} 8, \mathrm{O} 15$ and $\mathrm{O} 78$ which are considered to be one of the most prevalent and pathogenic serogroups in poultry farms. The higher percentage was $\mathrm{O} 1(35.3 \%)$ and $(31.4 \%)$ from the isolates of Tartos and Hama, respectively.

Key words: Echerichia coli, pathogenic, arthritis, serotyping

\section{INTRODUCTION}

Colibacillosis refers to any localized or systemic infection caused entirely or partly by avian pathogenic Echerichia coli (APEC), including colisepticemia, coligranuloma, yolk sac infection, air sacculitis, salpingitis, peritonitis, arthritis and others (Sharada et al., 2010). The most common forms of colibacillosis arthritis occurs among 2-10 week - old chickens (Aggad et al., 2006).

Escherichia coli is a part of the non-pathogenic normal inhabitants of intestinal and respiratory tracts in birds (Jordan and Pattison, 1996), so, it was considered as a potential pathogen. However, Escherichia coli infections in various farms are responsible for significant economic losses due to lower corporal development, insufficient feed conversion, increasing mortality, and higher cost of medicine (Rocha et al., 2008). Escherichia coli was the major cause of infections causing condemnation of processed chickens in Switzerland (Jacob et al., 1998).
However, arthritis caused by E. coli is a major cause of lameness in chicken. E. coli has been cultured from osteomyelitis, bacterial chondronecrosis and synovitis sites in previous studies (McNamee et al., 1998). Osteomyelitis may be seen in flock outbreaks of E. coli colibacillosis (Reece, 1992; Thorp, 1996) in association with septicemia, arthritis and tenosynovitis.

(Maurer et al., 1998) described that many E. coli isolates commonly associated with colibacillosis in poultry belong to serogroups $(\mathrm{O} 1, \mathrm{O} 6, \mathrm{O} 8, \mathrm{O} 15, \mathrm{O} 78)$, so these serogroups are more frequently recovered from Septicemic clinical cases (Heller and Drabkin, 1977; Cheville and Arp, 1998).

The rate of infection with E.coli bacteria (colibacillosis) is formed approximately $30-40 \%$ of the other diseases in poultry (Cheville and Arp, 1998). Serogroups (O1, O6, O8, O15, O78) are more pathogenic than other and more frequently associated with arthritis clinical cases (Barbour et al., 1970; Peighambari et al., 1995; Gomis et al., 2001). The 
previous studies have shown that hemolytic activities of APEC isolates correlated to the virulence of avian E. coli. In addition, approximately $90 \%$ of the isolates showed the hemolysis (alpha, beta, gamma) (Moon et al., 2006). Also, several authors (McNamee et al., 1998) had reported that E. coli which was isolated from femur of lameness birds was hemolytic (86.4\%).

The flagella, which are thin surface appendices, give motility to gram positive and negative bacteria in aqueous media. Their rotating movements allow microorganisms to approach adjacent epithelial cells, crossing the mucus barrier and causing adhesion, multiplication, colonization and infection (Stenutz et al., 2006).

This study aims to investigate the five frequently strains from $\mathrm{O}$ serogroups $(\mathrm{O} 1, \mathrm{O} 6, \mathrm{O} 8, \mathrm{O} 15, \mathrm{O} 78)$ and to test the motility and hemolysis characteristics of virulence factors.

\section{MATERIALS and METHODS}

\section{Samples Collection:}

During the period February 2012 to March 2013, a total of 188 joint samples of arthritis cases were collected from poultry farms in the middle and coastal regions of Syria (Hama and Tartos). Joints were subjected to cleaning and disinfection of the skin, then, exudates from swollen joints or foot pads were collected by sterilized swabs.

\section{Samples Preparation:}

Upon reaching the laboratory, samples were cultured in nutrient broth (HiMedia) overnight at $37^{\circ} \mathrm{C}$.

\section{Cultural and Biochemical characterization:}

The samples were cultured, using asterilized loop, on specific solid media MacConkey agar - EMB agar), then, incubated at $37^{\circ} \mathrm{C}$ for 24 hours.

All bacterial colonies were selected from each sample. These colonies were isolated in pure culture for further identification.
A cultural suspension with $5 \mathrm{ml}$ of physiological saline was prepared from each isolate and compared with McFarland standard to have a right turbidity. This material was used to inoculate HiMotility biochemical kit for E. coli (HiMedia) which include the following tests; Motility, Indole. Citrate, Glocoronidase, Nitrate, ONPG, Lysine, Lactose, Glucose, Sucrose and Sorbitol.

Kits were inoculated, incubated, handled, and analyzed according to the manufacturer's instructions.

\section{Motility test:}

The primary hanging Drop Method, as described by (Cowan, 1985), was carried out to detect the motility of all isolates. Isolates which didn't show motility had been retested by using SIM agar and incubated at $37^{\circ} \mathrm{C}$ for 24 hours (Quinn et al., 1994). In addition, results were supported with Biochemical kits which include a motility test.

\section{Hemolytic Test:}

The hemolysis of isolates was tested by culturing on blood agar and incubated at $37^{\circ} \mathrm{C}$ for 24 hours. The isolates which showed a complete hemolysis (Beta) on the blood agar had been recorded, as well as for the partial hemolysis (Alpha) and for the negative results (Gamma) (Quinn et al., 1994).

\section{Serotyping:}

We used five Serotypes (serum) of pathogenic E.coli (O1, O6, O8, O15, O78) [DENKA SEIKEN Co.Ltd, Tokyo, Japan]) (Veterinary Institute et al., 2009). Isolates were serotyped by agglutination test with specific antisera of somatic antigen to five serogroups (O1, O6, O8, O15, O78).

\section{RESULTS}

The articular region of affected hock, knee, hip and foot pad joints often appeared enlarged due to accumulated exudates distending into the joint cavity. Swelling was also observed as a result of periarticular inflammation of soft tissues and simultaneous tendovaginitis. The bacterial isolation from 188 cases of arthritis in chickens is shown in Table 1.

Table 1: Bacteriological results obtained from 188 investigated joints from chicken condemned due to arthritis.

\begin{tabular}{|c|c|c|c|c|c|c|c|c|}
\hline \multirow[t]{2}{*}{ Region } & \multirow{2}{*}{$\begin{array}{l}\text { Farms } \\
\text { involved }\end{array}$} & \multirow{2}{*}{$\begin{array}{c}\text { Number } \\
\text { of } \\
\text { samples }\end{array}$} & \multicolumn{4}{|c|}{ Examined Joints } & \multirow{2}{*}{$\begin{array}{l}\text { Isolate of } \\
\text { E. coli }\end{array}$} & \multirow[t]{2}{*}{ Isolates $\%$} \\
\hline & & & hip & Knee & hock & Foot pad & & \\
\hline Hama & 7 & 116 & 11 & 17 & 76 & 12 & 86 & 74.1 \\
\hline Tartos & 9 & 72 & 9 & 11 & 45 & 7 & 51 & 70.8 \\
\hline Total & 16 & 188 & 20 & 28 & 121 & 19 & 137 & 72.9 \\
\hline$\%$ & & & 14.6 & 20.4 & 88.3 & 13.9 & & \\
\hline
\end{tabular}

Collected exudates from joints had been cultured on MacConkey agar and all colonies were primary classified as E. coli based on the colonies characteristics (Table 2). 
$\underline{\text { Assiut Vet. Med. J. Vol. } 59 \text { No. } 138 \text { July } 2013}$

Table 2: Culture characteristics on MacConkey agar

\begin{tabular}{lll}
\hline Colonial morphology & Hama & Tartos \\
\hline Pink colonies- Lactose fermentation & $100 \%$ & $100 \%$ \\
\hline
\end{tabular}

The examination of 188 joint samples collected from Hama and Tartos revealed, that 95\% of Hama and 93\% of Tartosjoint samples were classified as E. coli isolates according to the results of Biochemical tests (using Bio.Kits) (Table 3).

Table 3-a: E. coli isolates after Biochemical tests (HiMotility Kits)

\begin{tabular}{lcc}
\hline & Hama & Tartos \\
\hline E. coli isolates after Biochemical tests & $95 \%$ & $93 \%$ \\
\hline
\end{tabular}

E. coli was gram negative rod. Catalase test was positive and oxidase test was negative. Indole production and Methyl-Red test were positive. Voges-Proskauer test and Simon's citrate were negative.

Table 3-b: Results of primary biochemical tests of E. coli

\begin{tabular}{lcccccccc}
\hline Isolates & Gram & Shape & Catalase & Oxidase & Indole & MR & VP & Citrate \\
\hline 137 & - & Rod & + & - & + & + & - & - \\
\hline
\end{tabular}

Table 3-c: Results of biochemical tests (HiMotility Kits)

\begin{tabular}{lccccccccccc}
\hline Isolates & MOTI & IND & CIT & GLOR & NIT & ONPG & LDC & LAC & GLU & SUC & SOR \\
\hline 137 & + & + & - & + & + & + & + & + & + & - & + \\
\hline
\end{tabular}

MOTI, Motility; IND, Indole; CIT, Citrate utilization; GLOR, Glocoronidase; NIT, Nitrate; ONPG,Ortho Nitrophenyl- $\beta D-G$ alactopyranosidas; LDC, Lysine decarboxylase; LAC, Lactose; SUC, sucrose; GLU, Glucose; SOR, Sorbitol. negative reaction + positive reaction

The detection of motility showed that, $95.3 \%$ of Hama and $95.1 \%$ of Tartosisolates were motile (Table 4).

Table 4: E. coli motility.

\begin{tabular}{lll}
\hline $\begin{array}{l}\text { Percentage of E. coli isolates } \\
\text { motile }\end{array}$ & Hama & Tartos \\
\cline { 2 - 3 } & $95.3 \%$ & $95.1 \%$ \\
\hline
\end{tabular}

Hemolysis test showed that, $95.7 \%$ of Hama isolates were hemolytic and $71.3 \%$ of them were type beta, while $94.6 \%$ of Tartos isolates were hemolytic and $75.1 \%$ were type beta (Table 5).

Table 5: Hemolysis on blood agar.

\begin{tabular}{lcc}
\hline & Hama & Tartos \\
\hline Hemolytic E. coli isolates & $95.7 \%$ & $94.6 \%$ \\
\hline Beta Hemolysis\% & 71.3 & 75.1 \\
\hline Alpha Hemolysis\% & 24.4 & 19.5 \\
\hline Gamma Hemolysis\% & 4.3 & 5.4 \\
\hline
\end{tabular}

$88.4 \%$ of Hama and $80.4 \%$ of Tartos isolates were motile and hemolytic at the same time.

Only 5 isolates from Hama and 5 isolates from Tartos were motile and non-hemolytic.

Only 5 isolates from Hama and 5 isolates from Tartos were hemolytic and non motile (Table 6). 
Assiut Vet. Med. J. Vol. 59 No. 138 July 2013

Table 6: Motility and hemolysis.

\begin{tabular}{lcc}
\hline & Hama & Tartos \\
\hline motile and hemolytic $\mathrm{n}(\%)$ & $76 / 86(88.4)$ & $41 / 51(80.4)$ \\
\hline motile and non-hemolytic $\mathrm{n}$ & 5 & 5 \\
\hline hemolytic and non motile $\mathrm{n}$ & 5 & 5 \\
\hline
\end{tabular}

The five serogroups $(\mathrm{O} 1, \mathrm{O} 6, \mathrm{O} 8, \mathrm{O} 15$ and $\mathrm{O} 78)$ formed a difference percentage in Hama and in Tartosisolates. O-serotype of pathogenic E. coli was O1(45 strains), O6(43), O8(5), O15(32), O78(12) (Table7).

Table 7: O-serotype of pathogenic E. coli

\begin{tabular}{lcccccc}
\hline & Isolates of E. coli & \multicolumn{5}{c}{ O-serotype of pathogenic E. coli } \\
\hline Hama & & O1 & O6 & O15 & O8 & O78 \\
\hline Tartos & 86 & $27(31.4 \%)$ & $25(29.06 \%)$ & $21(24.4 \%)$ & $4(4.7 \%)$ & $9(10.5 \%)$ \\
\hline Total & 51 & $18(35.3 \%)$ & $18(35.3 \%)$ & $11(21.6 \%)$ & $1(1.2 \%)$ & $3(5.9 \%)$ \\
\hline
\end{tabular}

\section{DISCUSSION}

In this study, the isolation trials resulted in detaining of 86 and 51 E. coli isolates (of 188 samples) from Hama and Tartos arthritis cases, respectively.

The results of this study showed that the most affected joints were hock and knee joints $(88.3 \%$, $20.4 \%$ ) respectively, this result is consistent with (Mutalib et al., 1996). On the other hand, (McNamee et al., 1998) reported that (13.6\%) of hip joints was affected, this result is similar with our's $(14.6 \%)$.

A percentage of $95.3 \%$ of Hama and $95.1 \%$ of Tartos isolates were motile, these percentages show a high level comparing with the results of other studies. In a recent study (Rocha et al., 2008), motility was detected in $54.1 \%$ of the samples and was $36.8 \%$ higher than that had been reported by (McPeake et al., 2005).

By testing the hemolysis of all isolates we found that percentage of hemolysis for the two regions isolates were approximately close even the percentage of hemolysis type, for example; $95.7 \%$ of Hama isolates was hemolytic and that was $94.6 \%$ for Tartos isolates.

The Beta hemolysis for Hama isolates was $71.3 \%$ and for Tartos isolates was $75.1 \%$. According to a recent study in Korea (Moon et al., 2006), it was found that $72 \%$ (48 isolates) of the APEC - isolated from birds with colibacillosis- revealed $\alpha$ or $\beta$ hemolysis on blood agar plates. In addition, approximately $90 \%$ of the isolates, which showed the hemolysis, harbored one or more virulence genes (Moon et al., 2006). So, this result gives a reasonable idea about the relationship between hemolysis characteristic and pathogenicity of strains.

The relationship between the two characteristics, motility and hemolysis were observed as $88.4 \%$ of Hama isolates and $80.4 \%$ of Tartos isolates which were found motile and hemolytic.

On the other hand, only 5 isolates from Hama and 5 isolates from Tartos were found motile and nonhemolytic, while 5 isolates from Hama and 5 isolates from Tartos were found hemolytic and non-motile.

In conclusion, the majority of the motile isolates (76 isolates/86 for Hama and 41 isolates/51 for Tartos) were carrying the hemolytic characteristic and showed a Beta or Alpha hemolysis on blood agar.

The results showed that the five serogroups exist in the two regions with different percentages. The most predominant serotype was O1(45 strains) accounting for 32.8\% and O6(43), O15(32), O8(5), O78(12). (Gomis et al., 2001) reported that E. coli of serogroups O1, O2, O78 isolated from avian colibacillosis predominantly in Canada. (Sojka and Carnaghan, 1961; Dho-Moulin and Fairbrother, 1999) described that many $\mathrm{E}$. coli isolates commonly associated with colibacillosis in poultry belong to serogroups O1, O2, O78. The serotypes of E. coli in the present study were in similar with (Sojka and Carnaghan, 1961; Dho-Moulinand Fairbrother, 1999; Gomis et al., 2001). On the other hand, (Sharada 
et al., 2010) reported that serotyping of isolates revealed redominantly $\mathrm{O} 11, \mathrm{O} 79, \mathrm{O} 111$ accounting for $26.15 \%$, but 015 , O78 were with very low percentage. So, we should more examine serotypes of isolated E. coli.

The serotype of E. coli O8 was isolated from 5 isolates and (Raji et al., 2003) reported that O8strain showed 100\% mortality in 1 day-old chickens and was the most pathogenic serotype.

In this study, it was found that several serotypes were determined. This report is the first report of E. coli serotyping isolated from poultry with lameness and arthritis in Syria.

In conclusion, utilization of Biochemical Kits for detecting the characteristics of E. coli strains is more suitable and easier than using the standard techniques. It gives accurate results and save time, although it is more expensive.

It is remarkable that five serogroups (O1, O6, O8, O15, O78) were existed in Hama and Tartos regions of Syria with a high percentage and this isolates were holding pathogenic characteristics like hemolysis and motility. Our results were similar to the previous reports, so, these five serogroups are considered the most prevalent and pathogenic serogroups in Syria.

We need a more detailed study in order to determine the relationship between different strains which isolated in the middle, coast and other regions of Syria. So, we need to establish the pathogenic characteristics. Ultimately, identification of potential virulence traits may allow for it as specific markers for the diagnosis of pathogenic strains.

\section{REFERENCES}

Aggad, H.; Ammar, A.; Hammoudi, A. and Kihal, M. (2006): Antibioresistance of E. coli strains isolated from chicken colibacillosis in western Algeria. (123-126).

Barbour, S.D.; Nagaishi, H.; Templin, A. and Clark, A.J. (1970): Biochemical and genetic studies of recombination proficiency in Escherichia coli. II. Rec + revertants caused by indirect suppression of rec- mutation. ProcNaltAcadSci U S A. 67(1): 128-135.

Cheville, N.F. and Arp, L.H. (1998): Comparative pathologic findings of Escherichia coli infection in birds. Journal of American Vet. Med Association., 137: 27-31.

Cowan, S.T. (1985): Biochemical behavior of E. coli. Journal of General Microbiology 8: 391.

Dho-Moulin, M. and Fairbrother, J.M. (1999): Avian Pathogenic Escherichia Coli (APEC). Vet. Res., 30(2-3), 299-316.
Gomis, S.M.; Riddell, C.; Potter, A.A. and Allan, B.J. (2001): Phenotype and genotypic characterization of virulence factors of Escherichia coli isolated from broiler with simultaneous occurrence of cellulitis and other colibacillosis lesions. Can J. Vet. Res., (65), 1-6.

Heller, E.D. and Drabkin, N. (1977): Some characteristics of pathogenic E. coli strains. $\mathrm{Br}$ Vet. J. 133: 572-578.

Jakob, H.P.; Morgenstern, R.; Albicker, P. and Hoop, R.K. (1998): Reasons for condemnation of slaughtered broilers from two large Swiss producers. Schweiz Arch Tierheilkd 140: 60-64.

Jordan, F.T.W. and Pattison, M. (1996): Poultry Diseases, W.B. Saunders, London.

Maurer, J.J.; Lee, M.D.; Lobsinger, C.; Brown, T.; Maier, M. and Thayer, S.G. (1998): Molecular typing of avian Escherichia coli isolates by random amplification of polymorphic DNA. Avian Diseases 42: 431-451.

McNamee, P.T.; McCullagh, J.J.; Thorp, B.H.; Ball, H.J.; Graham, D.; McCullough, S.J.; McConaghy, D. and Smyth, J.A. (1998): Study of leg weakness in two commercial broiler flocks. Veterinary Record 143: 131-135.

McPeake, S.J.W.; Smyth, J.A. and Ball, H.J. (2005): Characterization of avian pathogenic Escherichia coli (APEC) associated with Colisepticaemia compared to faecal isolates from healthy birds. Northern Ireland, UK. 110(3-4): 245-253.

Moon, B.M.; Won, G.Y.; Choi, Y.Y.; Jin, J.K.; Oh, I.G.; Park, J.H.; Eo, S.K. and Lee, J.H. (2006): Isolation and characteristics of avian pathogenic Escherichia coli from birds associated with colibacillosis, Korea, $\mathrm{P}(61)$.

Mutalib, A.; Miguel, B.; Brown, T. and Maslin, W. (1996): Distribution of arthritis and osteomyelitis in turkeys with greenliver discoloration. Avian Dis 40: 661-664.

Peighambari, S.M.; Vailancourt, J.P.; Wilson, R.A. and Gyles, C.L. (1995): Characteristics of Escherichia coli isolates from avian cellulitis. Avian Diseases 39: 116-124.

Quinn, P.J.; Carter, M.E.; Markey, B.; Carter, G.R. and TajDolatshani, F. (1994): Clinical veterinary microbiology, Mosby, Elsevier Limited, London, PP: 209-236.

Raji, M.A.; Dekeye, J.O.; Kwaga, J.K.P. and Bale, J.O.O. (2003): In vitro and vivo pathogenicity studies of Escherichia coli isolated from poultry in Nigeria. Israel J. Vet. Med. 58(1).

Reece, R.L. (1992): The role of infectious agents in leg abnormalities in growing birds. In : Bone Biology and Skeletal Disorders in Poultry (Whitehead, C.C.,Ed.) Carfax, Oxford, PP. 231-263. 
Rocha, A.C.G.P.; Rocha, S.L.S.; Lima-Rosa, C.A.V.; Souza, G.F.; Moraes, H.L.S.; Salle, F.O.; Moraes, L.B. and Salle, C.T.P. (2008): Genes associated with pathogenicity of avian Escherichia coli (APEC) isolated from respiratory cases of poultry, Barazil. 28(3): 183-186.

Sharada, R.; Ruban, S.W. and Thiyageeswaran, M. (2010): Isolation, Characterization and Antibiotic Pattern of Escherichia coli isolated from poultry. Amer-Euro J. Sci. Res., 5(1), 18-22.

Sojka, W.J. and Carnaghan, R.B.A. (1961): Escherichia coli infection in poultry. Res. Vet. Sci., (2), 340-352.
Stenutz, R.; Weintraub, A. and Widmalm, G. (2006): The structuresof Escherichia coli Opolysaccharide antigens. FEMS MicrobiolRev 30: 382-403.

Thorp, B.H. (1996): Diseases of the musculoskeletal system. In: Poultry Disease (Jordan, F.T.W. and Pattison, M., Eds), W.B. Saunders, London,PP. 290-305.

Veterinary Institute, University of Constantine, Algeria (2009): Airborne bacterial contamination in two broilers in North-East of Algeria, Veterinary World Vol. 2(2), P49-50.

\section{التحري عن خمس مجموعات مصلية لجراثيم الإشريكية القولونية الطيرية الممرضة المعزولة من حالات التهاب مفاصل

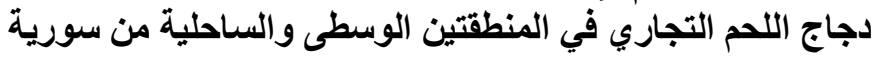$$
\text { نوال القزوانسي ، عزام كردي }
$$

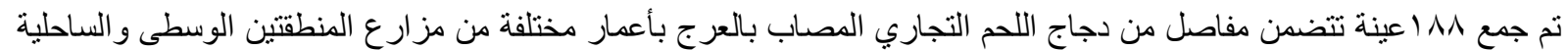

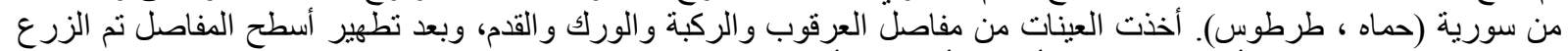

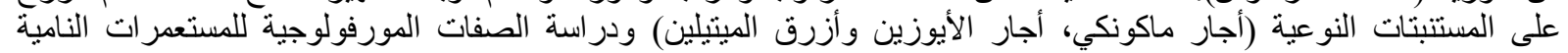

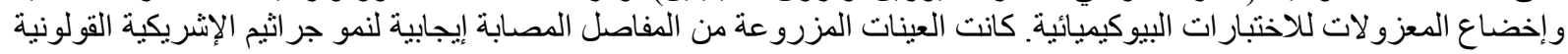

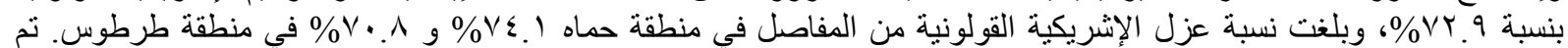

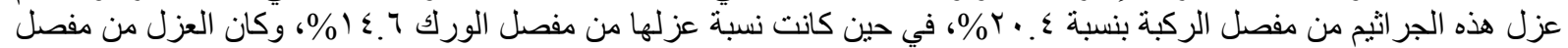

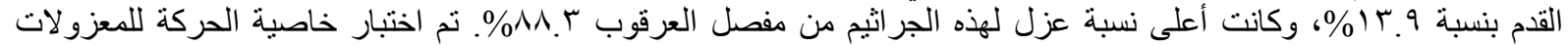

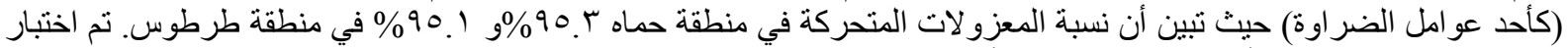

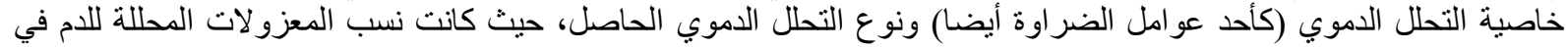

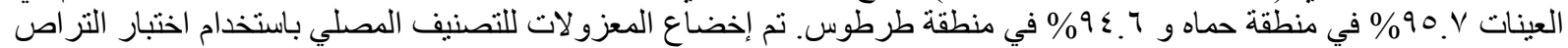

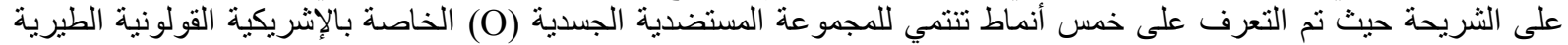

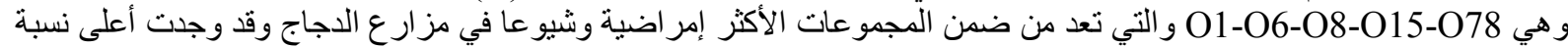

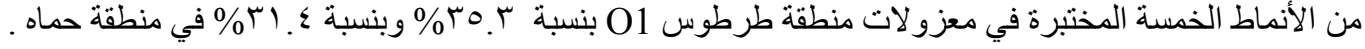

